\title{
Relationship between sex hormones and migraine
}

\author{
Gheyath AIGawwam* FIBMS
}

Abstract :

Back ground: Migraine is a common chronic episodic disabling primary headache disorder with associated Symptoms. The neuroendocrinological alterations, disorders of the hypothalamic-hypophysial axis are believed to be implicated in the pathogenesis of primary headache syndromes

Fac Med Baghdad 2015; Vol.57, No.1 Received: Dec., 2014 Accepted: Feb., 2015 Objective: The aim is to determine the effect of sex hormones on migraine.

Patients and methods: Twenty seven adult patients with migraine and 20 controls were assessed for prolactin,testeron,,LH,FSH were tested with immunofluorometric assay.

Results: This study found that migraine is associated with elevated level of FSH, prolactin and testerone $\mathrm{P}=$ $(<0.05),(<0.05)$ and $(<0.05)$ respectively .however there was no significant association between LH levels and migraine $\mathrm{P}(>0,05)$.

Conclusion: There is a significant correlation between levels of hormones and migraine.

Key word: Migraine, hormones.

\section{Introduction:}

Migraine is a very complex condition; in fact its physiopathology is not completely clear. It is believed that many neurotransmitters are implicated in this process, and hormones have been shown to play a major role in women. Among the neuroendocrinological alterations, disorders of the hypothalamic-hypophysial axis are believed to be implicated in the pathogenesis of primary headache syndromes. Premonitory symptoms in migraine suggest a transient hypothalamic dysfunction, such as polyuria, polydipsia, food craving and mood disturbances other authors who described the presence of headache in patients with microprolactinoma Referring to the type of headaches related to prolactinomas. (1) Migraine headache is strongly influenced by reproductive events that occur throughout the lifespan of women. Each of these reproductive events has a different "hormonal milieu," which might modulate the clinical course of migraine headache. Attacks of migraine with and without aura respond differently to changes in ovarian hormones. Clearly a greater knowledge of ovarian hormones and their effect on migraine is essential to a greater understanding of the mechanisms and pathogenesis of migraine headache (2),Epidemiological data suggest a link between migraine and the female sex hormones; Indeed, it is known that estrogen affects various brain functions, including pain perception. The prevalence of migraine is similar in boys and girls before puberty, but is 3-fold higher in postpubertal females compared with males. Migraine attacks in women are more likely to occur in the perimenstrual period and occur exclusively so in some women.(3), Migraine may worsen during the first trimester of pregnancy and, although many women become headachefree during the last two trimesters, have no change in their migraine. Migrain improves with pregnancy, perhaps due to sustained high estrogen levels ,hormonal replacement

\footnotetext{
*Baghdad college of medicine-neurology department.

E-mail:dr.ghayath@yahoo.com
}

with estrogens can exacerbate migraine and oral contraceptives (OCs) can change its character and frequency (4). During the transition to menopause some women may experience a worsening of the migraine attacks the observation that migraine is predominantly a female disorder and that several reproductive milestones correlate with a change in migraine frequency or type, implicates sex hormones in the pathogenesis of migraine. Sex steroids differentially influence migraine with aura and migraine without aura, the pathogenesis of menstrual migraine as of all changes in migraine related to hormones has not been fully characterized but appears to be related to estrogen withdrawal .(5)

\section{Patient and methods:}

Twenty seven adult patients with migraine and 20 control persons were collected from Baghdad teaching hospital out patient clinic, with aura and without aura of both sexes, the females were sent in their fifth days of menestural cycle for hormonal assessment of prolactin,testeron,,LH,FSH by immunofluorometric method.The males were also sent for the same hormonal assessment, carried out at the medical city central lab.

\section{Statistical Analysis:}

Statistical package for social sciences version 20 (SPSS 20) was used for data input and analysis. Continuous variables presented as means and discrete variables presented as numbers and percentages. ANOVA was used to test the significant of difference in mean levels of continuous variable and was replaced with Mann-Whitney test whenever the normality of distribution was under question. Chi-square test and Fisher's exact test used to test the significance of association between variables. Findings with $\mathrm{P}$ value less than 0.05 were considered significant. 


\section{Results:}

During a period of six months, we recruited 27 patients suffering

of migraine 6 of them were with aura and 21 without aura .Also 20 persons were selected as control group the migraine patients were 19 females and 8 males, the patients with aura were 10 and without aura were 17 .

Mean FSH,LH,prolactin,testeron levels were found to be significantly high in male/female migranous patients than in controls $(p<0.05$,table 1$)$, This study found that migraine is associated with elevated FSH level ( $p<0.05$,table 2$)$, there was no significant association between LH levels and migraine ( $>0,05$, table 2), Elevated prolactin is more likely to be associated with migraine (prevalence of elevated prolactin is $22 \%$ in migraine and $0 \%$ in control $)(\mathrm{p}<0.05$, table 2$)$. Migraine was found to be associated with elevated testeron level (40.7\%) compared to $0 \%$ ) in control $(\mathrm{p}<0.05$, table 2$)$, There was no significant association of aura with studied variable (sex,FSH level,LH level,prolactin level and testeron level) ( $\mathrm{p}>0.05$, table 3 ). Aura according to this study, showed no significant influence upon mean levels of each FSH,LH,prolactin,testerone levels in each gender $(p<0.05$, table 4$)$.
Table 1: Mean levels for biochemical variables for the study sample:

\begin{tabular}{|c|c|c|c|c|c|c|}
\hline & & \multicolumn{2}{|c|}{ Case } & \multicolumn{2}{|c|}{ Control } & \multirow{2}{*}{$\frac{P}{\text { value }}$} \\
\hline \multicolumn{2}{|c|}{ Variables } & Mean & SD & Mean & SD & \\
\hline \multicolumn{7}{|l|}{ FSH } \\
\hline$\bullet$ & Male & 12.2 & 3.6 & 4.5 & 2.2 & 0.001 \\
\hline$\bullet$ & Female & 13.8 & 4.5 & 5.8 & 2.4 & $<0.001$ \\
\hline \multicolumn{7}{|l|}{ LH } \\
\hline$\bullet$ & Male & 7.9 & 2.5 & 2.2 & 0.6 & $<0.001$ \\
\hline$\bullet$ & Female & 9.9 & 2.9 & 4.2 & 1.229 & $<0.001$ \\
\hline \multicolumn{7}{|c|}{ Prolactin } \\
\hline$\bullet$ & Male & 11.2 & 4.1 & 6.7 & 4.5 & 0.076 \\
\hline$\bullet$ & Female & 24.1 & 9.8 & 13.7 & 3.8 & 0.001 \\
\hline \multicolumn{7}{|c|}{ Testosterone } \\
\hline$\bullet$ & Male & 529.0 & 361.4 & 6.7 & 3.4 & 0.002 \\
\hline$\bullet$ & Female & 41.6 & 32.9 & 0.3 & 0.2 & $<0.001$ \\
\hline
\end{tabular}

NB) Difference in mean is significant if $\mathrm{P}<0.05$

Table 2: Distribution of study sample according to study group and to hormone status:

\begin{tabular}{|c|c|c|c|c|c|c|c|}
\hline \multirow[b]{2}{*}{ Variables } & \multicolumn{2}{|c|}{ Case } & \multicolumn{2}{|c|}{ Control } & \multicolumn{2}{|c|}{ Total } & \multirow[b]{2}{*}{$\mathbf{P}$} \\
\hline & $\mathrm{N}=\mathbf{2 7}$ & $100 \%$ & $\mathrm{~N}=\mathbf{2 0}$ & $\%$ & $\mathrm{~N}=47$ & $\%$ & \\
\hline$\overline{\text { FSH }}$ & & & & & & & $<0.001$ \\
\hline - Normal & 14 & $51.9 \%$ & 16 & $80.0 \%$ & 30 & $63.8 \%$ & \\
\hline - $\quad$ Elevated & 13 & $48.1 \%$ & $\mathbf{0}$ & $0.0 \%$ & 13 & $27.7 \%$ & \\
\hline - $\quad$ Decreased & $\mathbf{0}$ & $0.0 \%$ & 4 & $20.0 \%$ & 4 & $8.5 \%$ & \\
\hline - All & 27 & $100.0 \%$ & 20 & $100.0 \%$ & 47 & $100.0 \%$ & \\
\hline$\overline{\mathrm{LH}}$ & & & & & & & $0.242 \%$ \\
\hline - Normal & 25 & $92.6 \%$ & 19 & $95.0 \%$ & 44 & $93.6 \%$ & \\
\hline - $\quad$ Elevated & 2 & $7.4 \%$ & $\mathbf{0}$ & $0.0 \%$ & 2 & $4.3 \%$ & \\
\hline - $\quad$ Decreased & $\mathbf{0}$ & $0.0 \%$ & 1 & $5.0 \%$ & 1 & $2.1 \%$ & \\
\hline - All & 27 & $100.0 \%$ & 20 & $100.0 \%$ & 47 & $100.0 \%$ & \\
\hline Prolactin & & & & & & & $0.045 *$ \\
\hline - Normal & 21 & $77.8 \%$ & 19 & $95.0 \%$ & 40 & $85.1 \%$ & \\
\hline - $\quad$ Elevated & 6 & $22.2 \%$ & $\mathbf{0}$ & $0.0 \%$ & 6 & $12.8 \%$ & \\
\hline - $\quad$ Decreased & $\mathbf{0}$ & $0.0 \%$ & 1 & $5.0 \%$ & 1 & $2.1 \%$ & \\
\hline - All & 27 & $100.0 \%$ & 20 & $100.0 \%$ & 47 & $100.0 \%$ & \\
\hline Testosterone & & & & & & & 0.001 \\
\hline - Normal & 16 & $59.3 \%$ & 16 & $80.0 \%$ & 32 & $68.1 \%$ & \\
\hline - $\quad$ Elevated & 11 & $40.7 \%$ & $\mathbf{0}$ & $0.0 \%$ & 11 & $23.4 \%$ & \\
\hline - $\quad$ Decreased & $\mathbf{0}$ & $0.0 \%$ & 4 & $20.0 \%$ & 4 & $8.5 \%$ & \\
\hline - All & 27 & $100.0 \%$ & 20 & $100.0 \%$ & 47 & $100.0 \%$ & \\
\hline
\end{tabular}

*Minimum expected count is less than 1. $P$ value could be invalid

$\mathrm{NB}$ ) association is significant if $\mathrm{P}<0.05$ 
Table 3: Distribution of cases group according to presence of aura and to study factors:

\begin{tabular}{|c|c|c|c|c|c|c|c|}
\hline & & Case & & Control & & Total & \\
\hline Variables & $\mathbf{N}=\mathbf{2 7}$ & $100 \%$ & $\mathbf{N}=\mathbf{2 0}$ & $\%$ & $\mathrm{~N}=47$ & $\%$ & $\mathbf{P}$ \\
\hline Sex & & & & & & & 1.000 \\
\hline - $\quad$ Male & 2 & $33.3 \%$ & 6 & $28.6 \%$ & 8 & $29.6 \%$ & \\
\hline - $\quad$ Female & 4 & $66.7 \%$ & 15 & $71.4 \%$ & 19 & $70.4 \%$ & \\
\hline - $\quad$ All & 6 & $100.0 \%$ & 21 & $100.0 \%$ & 27 & $100.0 \%$ & \\
\hline FSH & & & & & & & 1.000 \\
\hline - $\quad$ Normal & 3 & $50.0 \%$ & 11 & $52.4 \%$ & 14 & $51.9 \%$ & \\
\hline - $\quad$ Elevated & 3 & $50.0 \%$ & 10 & $47.6 \%$ & 13 & $48.1 \%$ & \\
\hline - $\quad$ Decreased & $\mathbf{0}$ & $0.0 \%$ & $\mathbf{0}$ & $0.0 \%$ & $\mathbf{0}$ & $0.0 \%$ & \\
\hline - All & 6 & $100.0 \%$ & 21 & $100.0 \%$ & 27 & $100.0 \%$ & \\
\hline LH & & & & & & & 1.000 \\
\hline - Normal & 6 & $100.0 \%$ & 19 & $90.5 \%$ & 25 & $92.6 \%$ & \\
\hline - $\quad$ Elevated & $\mathbf{0}$ & $0.0 \%$ & 2 & $9.5 \%$ & 2 & $7.4 \%$ & \\
\hline - $\quad$ Decreased & 0 & $0.0 \%$ & 0 & $0.0 \%$ & $\mathbf{0}$ & $0.0 \%$ & \\
\hline - All & 6 & $100.0 \%$ & 21 & $100.0 \%$ & 27 & $100.0 \%$ & \\
\hline Prolactin & & & & & & & 0.588 \\
\hline - $\quad$ Normal & 4 & $66.7 \%$ & 17 & $81.0 \%$ & 21 & $77.8 \%$ & \\
\hline - $\quad$ Elevated & 2 & $33.3 \%$ & 4 & $19.0 \%$ & 6 & $22.2 \%$ & \\
\hline - $\quad$ Decreased & $\mathbf{0}$ & $0.0 \%$ & $\mathbf{0}$ & $0.0 \%$ & $\mathbf{0}$ & $0.0 \%$ & \\
\hline - All & 6 & $100.0 \%$ & 21 & $100.0 \%$ & 27 & $100.0 \%$ & \\
\hline Testosterone & & & & & & & 0.187 \\
\hline - $\quad$ Normal & 2 & $33.3 \%$ & 14 & $66.7 \%$ & 16 & $59.3 \%$ & \\
\hline - $\quad$ Elevated & 4 & $66.7 \%$ & 7 & $33.3 \%$ & 11 & $40.7 \%$ & \\
\hline - $\quad$ Decreased & $\mathbf{0}$ & $0.0 \%$ & $\mathbf{0}$ & $0.0 \%$ & $\mathbf{0}$ & $0.0 \%$ & \\
\hline - All & 6 & $100.0 \%$ & 21 & $100.0 \%$ & 27 & $100.0 \%$ & \\
\hline
\end{tabular}

Table 4: Mean levels for biochemical findings in cases group according to presence of aura and to the sex of patients:

\begin{tabular}{|c|c|c|c|c|c|c|}
\hline \multirow{2}{*}{\multicolumn{2}{|c|}{ Variables }} & \multicolumn{2}{|c|}{ Aura } & \multicolumn{2}{|c|}{ No Aura } & \multirow{2}{*}{$\begin{array}{c}\mathbf{P} \\
\text { Value }\end{array}$} \\
\hline & & Mean & SD & Mean & SD & \\
\hline \multicolumn{7}{|l|}{ FSH } \\
\hline$\bullet$ & Male & 8.9 & 4.4 & 13.2 & 3.0 & 0.154 \\
\hline$\bullet$ & Female & 16.7 & 6.5 & 13.0 & 3.8 & 0.160 \\
\hline • & All & 14.1 & 6.7 & 13.1 & 3.5 & 0.629 \\
\hline \multicolumn{7}{|l|}{ LH } \\
\hline$\bullet$ & Male & 8.5 & 2.1 & 7.8 & 2.8 & 0.745 \\
\hline • & Female & 10.5 & 1.3 & 9.7 & 3.2 & 0.650 \\
\hline$\bullet$ & All & 9.8 & 1.7 & 9.2 & 3.2 & 0.626 \\
\hline \multicolumn{7}{|c|}{ Prolactin } \\
\hline$\bullet$ & Male & 9.0 & 0.0 & 11.9 & 4.6 & 0.432 \\
\hline$\bullet$ & Female & 25.5 & 9.4 & 23.7 & 10.2 & 0.759 \\
\hline$\bullet$ & All & 20.0 & 11.2 & 20.3 & 10.4 & 0.945 \\
\hline \multicolumn{7}{|c|}{ Testosterone } \\
\hline$\bullet$ & Male & 633.0 & 165.5 & 494.3 & 414.2 & 0.867 \\
\hline$\bullet$ & Female & 41.3 & 46.5 & 41.7 & 30.5 & 0.764 \\
\hline$\bullet$ & All & 238.5 & 316.4 & 171.0 & 295.7 & 0.540 \\
\hline
\end{tabular}




\section{Discussion:}

This study shows mean FSH and LH level is significanly high in male/female migranous patients than in control group ( $p<0.05$,table 1) but also found that migraine is associated with elevated FSH level $(p<0.05$,table2)and this result is compatible with Elwan etal study in which FSH and LH showed detectable levels in all headache sufferers compared to undetectable levels in control subjects(6), but at same time shows there was no significant association between $\mathrm{LH}$ levels and migraine $(p>0,05)$, The M.T Epstein etal study showed no specific hormone changes were associated with the occurrence of a migraine attack, nor did rising or falling levels and this is against our result(7). This study shows mean prolactin level is significanly high in male/female migranous patients than in control $(\mathrm{p}<0.05)$ also shows elevated prolactin is more likely to be associated with migraine (prevalence of elevated prolactin is $22 \%$ in migraine and $0 \%$ in control) $(\mathrm{p}<0.05)$;in Bosco D1 study showed that prolactin (PRL) levels measured during attacks of headache were significantly higher in nine patients $(56 \%)$ of migranous patient suggested that hyperprolactinemia may contribute to development of pain in migraine subgroups(8); in Cinzia Cavestro etal study mentioned that PRL levels should always be considered when headache worsens. It is an adjunctive worsening factor, which can be easily eliminated.(1) . M.T Epstein etal study shows Mean plasma-prolactin levels were lower in migraine subjects than controls, but the difference was not significant (7) and this disagree with our results. This study shows mean testerone level is significanly high in male/female migranous patients than in control $(\mathrm{p}<0.05)$ also migraine was found to be associated with elevated testeron level (40.7\%)compared to $(0 \%)$ in control $(\mathrm{p}<0.05)$ this results incompatable with Robert $\mathrm{F}$ etal which shows no significant difference in plasma testosterone levels could be detected.(9)

This study shows no significant association of aura with studied variable (sex,FSH level,LH level,prolactin level and testeron level) ( $p>0.05$ ) also aura according to this study ,showed no significant influence upon mean levels of each FSH,LH,prolactin,testerone levels in each gender $(\mathrm{p}<0.05$, table 4) no study found to support or against this study . Attacks of migraine with and without aura respond differently to changes in ovarian hormones. Clearly a greater knowledge of ovarian hormones and their effect on migraine is essential to a greater understanding of the mechanisms and pathogenesis of migraine headache.(2).

\section{Refrences:}

1- Cinzia Cavestro ,Annalisa Rosatello,Maria Pia Marino,Gianmatteo Micca,Giovanni Asteggiano ,High prolactin levels as a worsening factor for migraine. J Headache Pain (2006) 7:83-89

2- Vincent T. Martin MD and Michael Behbehani PhD
Ovarian Hormones and Migraine Headache: Understanding Mechanisms and Pathogenesis-Part 2 Headache: The Journal of Head and Face Pain Volume 46, Issue 3, pages 365-386, March 2006.

3-Ashkenazi A1, Silberstein SD, Hormone-related headache: pathophysiology and treatment.CNS Drugs. 2006;20(2):12541.

4-Silberstein SD, Sex hormones and headache.Rev Neurol (Paris). 2000;156 Suppl 4:4S30-41.

5-Simona Sacco • Silvia Ricci • Diana Degan •Antonio Carolei. Migraine in women: the role of hormones and their impact on vascular diseases. J Headache Pain (2012) 13:177-189.

6-Elwan O, Abdella M, el Bayad AB, Hamdy S Hormonal changes in headache patients.. Journal of the Neurological Sciences [1991, 106(1):75-81.

7-M.T Epstein, J.M Hockaday, T.D.R Hockaday, MIGRAINE AND REPRODUCTIVE HORMONES THROUGHOUT THE MENSTRUAL CYCLE .The Lancet, Volume 305, Issue 7906, Pages 543 - 548, 8 March 1975.

8-Bosco D1, Belfiore A, Fava A, De Rose M, Plastino $M$, Ceccotti $\quad C$, Mungari $\quad P$, Iannacchero $\quad R$, Lavano A , Relationship between high prolactin levels and migraine attacks in patients with microprolactinoma.J Headache Pain (2008) 9:103-107.

9- Robert F. Nelson M.D., F.R.C.P. Testosterone Levels in Cluster and Non-Cluster Migrainous Headache Patients, Headache: The Journal of Head and Face PainVolume 18, Issue 5, pages 265-267, November 1978. 